\title{
Reduced Graphene/Polydopamine-Supported Au@Pt/Au Nanoparticles for Electrochemical Detection of Acetaminophen
}

\author{
Ling Shi ${ }^{1,2}$, Zefeng Wang ${ }^{1,2, *}, N a W^{1,2}$, Xianlan Chen ${ }^{1,2}$, Guangming Yang ${ }^{1,2, *}$, Wei Liu $^{1,2, *}$ \\ ${ }^{1}$ School of science, Honghe University, mengzi, Yunnan 661199, PR China \\ ${ }^{2}$ Key Laboratory of Natural Pharmaceutical \& Chemical Biology of Yunnan Province, Mengzi, \\ Yunnan 661199, PR China \\ *E-mail: wangzefeng841006@ 163.com, yangguangmingbs@ @126.com, liuwei4728@ 126.com
}

doi: $10.20964 / 2020.05 .78$

Received: 13 January 2020 / Accepted: 8 March 2020 / Published: 10 April 2020

In this work, we report an efficient electrochemical sensor made from reduced graphene/polydopamine supported Au@Pt/Au (GN/PDA/Au@Pt/Au) nanoparticles for detection of acetaminophen (ACOP). The electrochemical reaction mechanism is investigated using cyclic voltammetry (CV). The Electrocatalytic activity is monitored under varying $\mathrm{pH}$. The ACOP is detected under the optimal condition. A linear range from 1 to $300 \mu \mathrm{M}$ is achieved with a limit of detection of $0.31 \mu \mathrm{M}$. The fabricated sensor show satisfactory results in commercial tablets.

Keywords: graphene; polydopamine; Au; Pt; electrochemical sensor; acetaminophen

\section{$\underline{\text { FULL TEXT }}$}

(C) 2020 The Authors. Published by ESG (www.electrochemsci.org). This article is an open access article distributed under the terms and conditions of the Creative Commons Attribution license (http://creativecommons.org/licenses/by/4.0/). 